$\begin{array}{cc}\text { Araştırma Makalesi / Research Article } & \text { Harran Tarım ve Gıda } \\ \text { Gilimleri Dergisi (2017) } & \text { 21(2): 219-226 } \\ \text { Geliş tarihi: 06.11.2016 } & \text { Kabul tarihi: 16.02.2017 }\end{array}$

\title{
Kilis Keçilerinin Canlı Ağırık ve Bazı Vücut Ölçüleri Üzerinde Cinsiyet Etkisinin Belirlenmesi
}

\author{
Adnan ÜNALAN ${ }^{1 *}$, Ayhan CEYHAN ${ }^{2}$ \\ ${ }^{1}$ Ömer Halisdemir Üniversitesi, iktisadi ve Idari Bilimler Fakültesi, İşletme Bölümü, 51240 Merkez, Niğde \\ 2 Ömer Halisdemir Üniversitesi, Bor Meslek Yüksekokulu, Veterinerlik Bölümü, 51700 Bor, Niğde \\ *Sorumlu Yazar: unalanadnan@gmail.com
}

\begin{abstract}
Öz
Bu çalışma, farklı yaşlardaki Kilis keçilerinin canlı ağırıkları ile diğer bazı vücut özelliklerinin tespit edilmesi ve bu özellikler üzerindeki cinsiyet etkisinin belirlenmesi amacıyla yürütülmüştür. Çalışmada, Kilis merkez ilçedeki iki yetiştiricinin Kilis keçisi sürüsünde bulunan toplam 201 baş keçi (34 baş erkek ve 167 baş dişi) kullanılmıştır. Erkekler için canlı ağırlık, vücut uzunluğu, cidago yüksekliği, göğüs genişliği, sırt yüksekliği, sağrı yüksekliği, göğüs çevresi, göğüs derinliği, kulak uzunluğu ve ön incik çevresi genel ortalamaları sırasıyla $59.68 \pm 3.64 \mathrm{~kg}, 74.07 \pm 1.55 \mathrm{~cm}, 76.24 \pm 1.49 \mathrm{~cm}, 21.57 \pm 0.55 \mathrm{~cm}, 72.29 \pm 1.29 \mathrm{~cm}$, $73.22 \pm 1.24 \mathrm{~cm}, 95.50 \pm 2.06 \mathrm{~cm}, 31.99 \pm 0.68 \mathrm{~cm}, 30.79 \pm 0.53$ ve $10.88 \pm 0.26 \mathrm{~cm}$ olarak; dişiler için ise $41.43 \pm 0.70 \mathrm{~kg}, 69.75 \pm 0.48 \mathrm{~cm}, 69.06 \pm 0.38 \mathrm{~cm}, 20.81 \pm 0.20 \mathrm{~cm}, 67.45 \pm 0.44 \mathrm{~cm}, 68.80 \pm 0.37 \mathrm{~cm}$, $86.85 \pm 0.55 \mathrm{~cm}, 30.21 \pm 0.23 \mathrm{~cm}, 29.92 \pm 0.22 \mathrm{~cm}$ ve $9.00 \pm 0.06 \mathrm{~cm}$ olarak bulunmuştur. Incelenen bu özelliklerin cinsiyetlere göre genel ortalamaları karşılaştıııldığında, göğüs genişliği ve kulak uzunluğu dışındaki $(P>0.05)$ diğer özelliklerin genel ortalamaları arasındaki fark önemli $(P<0.01)$ çıkmıştır. Ayrıca, bir yaşındaki keçilerde tüm bu özelliklerin ortalamaları arasındaki fark önemsiz $(P>0.05)$, daha sonraki yaşlardaki keçilerde ise kulak uzunluğu ve göğüs genişliği dışındaki diğer özelliklerin ortalamaları arasındaki farklar ise önemli $(\mathrm{P}<0.01)$ bulunmuştur. Tüm bu sonuçlardan, cinsiyet etkisinin Kilis keçilerinin göğüs genişliği ve kulak uzunluğu dışındaki diğer vücut özellikleri ile canlı ağırıkları üzerinde önemli olduğu; ancak, bu etkinin bir yaşından sonra ortaya çıktığı ( 3 yaş göğüs derinliği dışında) sonucuna varılmıştır. Ayrıca, canlı ağırlık ile sırt yüksekliği dışında $(r=0.10, P>0.05)$ diğer vücut özellikleri arasındaki ilişkinin de pozitif $(r=0.44$ ile 0.89 arasında) ve istatistik olarak önemli $(P<0.01)$ olduğu görülmüştür. Bu bulgulardan, keçilerde yapılacak ıslah çalışmalarında dolaylı seleksiyon için canlı ağırlık ile yüksek ilişkili diğer vücut ölçülerinin kullanılabileceği sonucu çıkarılabilir.
\end{abstract}

Anahtar Kelimler: Kilis keçisi, Canlı ağırlık, Vücut ölçüleri, Korelasyonlar

\section{Determination of Sex Effect on Body Weight and Some Body Measurements of Kilis Goat}

\begin{abstract}
This study was conducted with the aim of investigating body weight and some other body characteristics of Kilis goat in different ages and determining the sex effect on these body characteristics. In the study, a total of 201 goats (34 males and 167 females) in two private Kilis goat herds in central district of Kilis province were used. The overall means of body weight, body length, withers height, chest width, ridge height, rump height, chest girth, chest depth, ear length and fore cannon girth of males were 59.68 \pm 3.64 $\mathrm{kg}, 74.07 \pm 1.55 \mathrm{~cm}, 76.24 \pm 1.49 \mathrm{~cm}, 21.57 \pm 0.55 \mathrm{~cm}, 72.29 \pm 1.29 \mathrm{~cm}, 73.22 \pm 1.24 \mathrm{~cm}, 95.50 \pm 2.06 \mathrm{~cm}$, $31.99 \pm 0.68 \mathrm{~cm}, 30.79 \pm 0.53$ and $10.88 \pm 0.26 \mathrm{~cm}$ respectively; they were $41.43 \pm 0.70 \mathrm{~kg}, 69.75 \pm 0.48 \mathrm{~cm}$, $69.06 \pm 0.38 \mathrm{~cm}, 20.81 \pm 0.20 \mathrm{~cm}, 67.45 \pm 0.44 \mathrm{~cm}, 68.80 \pm 0.37 \mathrm{~cm}, 86.85 \pm 0.55 \mathrm{~cm}, 30.21 \pm 0.23 \mathrm{~cm}$, $29.92 \pm 0.22 \mathrm{~cm}$ and $9.00 \pm 0.06 \mathrm{~cm}$ respectively for females. When comparing the overall means of these body characteristics according to sex, the overall mean differences of the traits were seen statistically significant $(P<0.01)$, except for chest width and ear length $(P>0.05)$. Besides, it was also found that the mean difference between all of these characteristics in first age group was not significant $(P>0.05)$. But,
\end{abstract}


except for ear length and chest width, the mean difference between these body characteristics were all statistically significant in later age groups $(\mathrm{P}<0.01)$. All these results indicated that the sex had important effect on the body weights of Kilis goats, other than the chest width and ear length; however, the effect of sex was important in later ages of goats (except for chest depth of 3 years age group). In addition, it was also determined that the correlations between body weight and other body characteristics except for ridge height $(r=0.10, P>0.05)$ which were also positive $(r=0.44$ to 0.89$)$ and statistically significant $(P<0.01)$. From these findings, it can be conclued able to use of the other body measurements highly correlated with body weight for indirect selection in breeding studies on goats.

Key Words: Kilis goat, Body weight, Body measurements, Correlations

Giriş

Türkiye'de evcil hayvan türleri arasında keçinin önemli bir yeri vardır ve ekonomik önemi olan türlerden birisidir. Bunu keçinin ilk evcilleştirilen hayvan türlerinden birisi olmasına, değişik çevre koşullarına kısa sürede uyum göstermesine ve kültürümüzde yüzyıllardır var olmasına bağlayabiliriz. Keçi yetiştiriciliğinin yaygın olduğu bölgeler doğa ve yaşam koşullarının güç, bitkisel üretim olanaklarının son derece sınırlı olduğu yerlerdir. Keçi yetiştiriciliği insan beslenmesine temel besin maddesi olan et ve süt ihtiyacını karşılaması, elde edilen ürünlerin insan sağlığı bakımından üstün özellikler taşıması, ülke ekonomisine istihdam sağlaması, farklı iş kollarına girdi oluşturması, elverişsiz alanlardan yüksek düzeyde faydalanması ayrıca gelişmiş ülkelerde keçi ürünlerine talebin artması gibi nedenlerden dolayı yapılması gereken önemli bir hayvancilık koludur (Ceyhan, 2016).

Ülkemizde 2015 yılı verilerine göre 10.416.166 baş keçi yetiştirilmektedir. Bu keçilerin \%44.0'ü (4.578.494 baş) sağılmakta ve 481.174 ton süt üretilmektedir. Sağılan hayvan başına ortalama süt verimi ise 105 kg'dır. Keçilerin \%19.2'si (1.999.241 baş) kasaplık olarak değerlendirilmekte ve 33.990 ton et elde edilmektedir. Ülkemizde toplam süt üretimi 18.654 .682 ton ve kırmızı et üretimi de 1.149.262 ton'dur. Keçiler, ülkemizdeki süt üretiminin yaklaşık $\% 2.6$ 'sını ve kırmızı et üretiminin \%3.0'ünü karşılamaktadır (TÜiK, 2016).

Türkiye'de keçi yetiştiriciliği, yıllardan beri düşük gelir katmanı çiftçilerin bir bölümünün geçim kaynağı olarak nitelendirilmiştir. Buna karşılık son dönemlerde büyük sermayeler yatırılarak, daha bilinçli üretim yapan işletmeler de kurulmaktadır. Keçi yetiştiriciliğinde yaşanan bu değişim Türkiye keçi populasyonunun yaklaşık \%97-98'ini oluşturan Kıl keçilerin yerine Saanen, Şam keçisi gibi daha verimli ırkların yetiştirilmesini de beraberinde getirmiştir. Zira düşük verimli Kıl keçiler entansif üretime uygun görülmemektedir. Keçi yetiştiriciliğinde yaşanan yapısal değişiklik; genetik yapının iyileştirilmesinin yanında, bakım-besleme başta olmak üzere çevresel şartların iyileştirilmesini de gerektirmektedir (Keskin ve Tüney, 2015).

Türkiye İstatistik Kurumu verilerinde ülkemiz keçi varlığının hemen hemen tamamı Kıl keçisi olarak ifade edilmektedir. Oysa, resmi istatistiklerde yer almamasına rağmen ülkemizde 200 bin civarında Kilis keçisi de bulunmaktadır (Özcan, 1989). Yerli keçi ırklarımızdan birisi olan ve yerli Kıl keçilerle Damaskus keçilerin melezi olan ve uzun yıllar sonunda ülkemizde ayrı bir ırk haline gelen Kilis keçileri, başta Kilis ve Gaziantep olmak üzere Güneydoğu Anadolu Bölgesinde yaygın olarak yetiştirilen keçi ırklarından birisidir (Ünalan, 2007). Aynı zamanda yerli 
keçi ırkları içerisinde süt verimi de yüksek olan bir ırktır. Genelde siyah ve kahverengidir, alacalı olanlara da rastlanır. Meme yapısı çok iyi gelişmiş olup, sarkık meme tipindedir. Kötü çevre koşullarına ve hastalıklara dayanaklıdır. Kulaklar çok uzun, geniş ve sarkıktır ortalama $26 \mathrm{~cm}$ kadardır. Ergin keçilerde canlı ağırlık $35-45 \mathrm{~kg}$, tekelerde 55-65 kg arasındadır. Kilis keçilerinin laktasyon süt verimi 70.3-269.9 kg'dır. Doğuran 100 keçiden 132.3 oğlak alınabilmektedir (Anonim, 2004).

Vücut ölçülerine ilişkin çalışmaların farklı yıllarda ve işletmelerde yapılması, ırkların tanımlanması için son derece önemlidir. Bu çalışma, ülkemizdeki evcil hayvan genetik kaynaklarımız arasında önemli bir yeri olan Kilis keçilerinde, farklı yaşlardaki keçilerde canlı ağırlık ve bazı vücut ölçülerinin (vücut uzunluğu, cidago yüksekliği, göğüs çevresi, sırt yüksekliği, sağrı yüksekliği, göğüs derinliği, kulak uzunluğu ve incik çevresi) cinsiyetlere göre karşılaştırmalı olarak incelenmesi ve bu özellikler arasındaki ilişkilerin belirlenmesi amacıyla yürütülmüştür.

\section{Materyal ve Metot}

Çalışmanın hayvan materyalini, Kilis merkez Başmağara köyü ve Kalleş mevkiindeki iki yetiştiricinin sürüsündeki 1,2 , 3,4 ve 5 yaş ve üzeri toplam 34 baş erkek ve 167 baş Kilis keçisi oluşturmuştur. Illde keçi yetiştiriciliğindeki temel uygulamalar (çiftleştirme, bakım, besleme, sağlık koruma, barındırma ve sürü idaresi vb.) bölgenin mevcut şartlarına uygun olarak çoğunlukla geleneksel yöntemlerle yapılmaktadır.

Araştırmada değerlendirilen erkek ve dişi keçilerin canlı ağırlıkları Haziran ayı içerisinde $100 \mathrm{~g}$ hassasiyete sahip kantar ile ölçülmüştür. Keçilerde önemli sayılan morfolojik yapıyı belirlemeye yardımcı olacak diğer vücut ölçülerinden; vücut uzunluğu, cidago yüksekliği, göğüs genişliği, sırt yüksekliği, sağrı yüksekliği ölçü batonu ile, göğüs çevresi, kulak uzunluğu ve incik çevresi ölçüleri ise şeritmetre kullanarak, düz bir alanda keçiler sakinleştirildikten sonra, Özcan (1989)'ın bildirdiği yönteme göre ölçü bastonu ve şerit metre kullanılarak alınmıştır.

Araştırmadaki verilerin istatistik analizinde, önce farklı yaş ve cinsiyetteki Kilis keçilerinin canlı ağırlık ve diğer incelenen vücut ölçülerine ait tanımlayıcı istatistikler her bir yaş grubu ve genel ortalama değerler şeklinde SPSS Ver. 17.0 paket programı (SPSS, 2004) kullanılarak bulunmuştur. Daha sonra her bir yaş grubu ve genel değerler için cinsiyetin incelenen bu özellikler üzerinde önemli etkiye sahip olup-olmadığının belirlenmesi amacıyla tek yönlü varyans analizi (One-way Analysis of Variance: ANOVA) kullanılmıştır. Son olarak da incelenen tüm bu özellikler arasındaki ilişkilerin belirlenmesi amacıyla Pearson korelasyon katsayıları hesaplanmıştır (SPSS, 2004).

\section{Araştırma Bulguları ve Tartışma}

Farklı yaş ve cinsiyetteki Kilis keçilerinde canlı ağırlık, vücut uzunluğu, cidago yüksekliği, göğüs çevresi, sırt yüksekliği, sağrı yüksekliği, göğüs derinliği, kulak uzunluğu ve incik çevresine ait ortalamalar $( \pm$ standart hata) Çizelge 1'de verilmiştir. 
Çizelge 1. Kilis keçilerinin incelenen vücut özelliklerine ait en küçük kareler ortalamaları ve standart hataları

Table 1. The least square means and standard errors of the body characteristic of Kilis goat

\begin{tabular}{|c|c|c|c|c|c|c|c|c|c|c|c|}
\hline Yaş (Age) & 1 & & 2 & & 3 & & 4 & & $5+$ & & $\begin{array}{l}\text { Ortalama } \\
\text { (Mean) }\end{array}$ \\
\hline haracteristic) n & $X \pm S x$ & $\mathrm{n}$ & $X \pm S x$ & $\mathrm{n}$ & $X \pm S x$ & $\mathrm{n}$ & $X \pm S x$ & $\mathrm{n}$ & $X \pm S x$ & $\mathrm{~N}$ & $X \pm S x$ \\
\hline
\end{tabular}

Canlı ağırlık, kg (body weight, kg)

Erkek (Male) $9229.20 \pm 2.22768 .70 \pm 2.691071 .35 \pm 3.99 \quad 471.23 \pm 10.56471 .78 \pm 2.16 \quad 3459.68 \pm 3.64$ Dişi (Female) $\quad 2528.22 \pm 1.243540 .47 \pm 1.175944 .70 \pm 0.85 \quad 3544.92 \pm 1.44 \quad 1345.14 \pm 1.56 \quad 16741.43 \pm 0.70$

\begin{tabular}{lllllll}
$\mathrm{P}$ & ÖD (NS) & $* *$ & $* *$ & $* *$ & $* *$ & $* *$ \\
\hline
\end{tabular}

Vücut uzunluğu, $\mathrm{cm}$ (body length, $\mathrm{cm}$ )

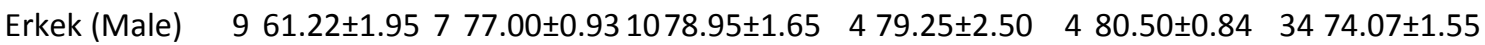
Dişi (Female) $\quad 2560.78 \pm 1.153570 .61 \pm 0.905971 .27 \pm 0.61 \quad 3571.69 \pm 0.85 \quad 1372.50 \pm 0.80 \quad 16769.75 \pm 0.48$

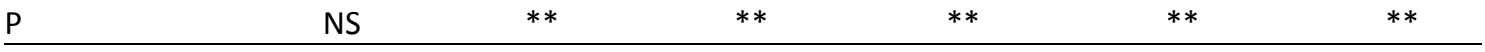

Cidago yüksekliği, cm (withers height, $\mathrm{cm}$ )

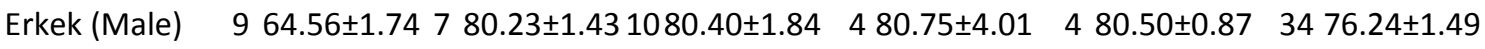
Dişi (Female) $\quad 2562.84 \pm 1.003569 .74 \pm 0.685970 .27 \pm 0.61 \quad 3570.20 \pm 0.58 \quad 1370.62 \pm 0.76 \quad 16769.06 \pm 0.38$ \begin{tabular}{lllllll}
$\mathrm{P}$ & ÖD (NS) & $* *$ & $* *$ & $* *$ & $* *$ & $* *$ \\
\hline
\end{tabular} Gögüs genişliği, $\mathrm{cm}$ (chest width, $\mathrm{cm}$ )

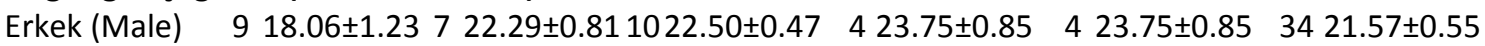
Dişi (Female) $\quad 2517.42 \pm 0.653520 .93 \pm 0.225921 .47 \pm 0.25 \quad 3521.67 \pm 0.41 \quad 1321.69 \pm 0.29 \quad 16720.81 \pm 0.20$

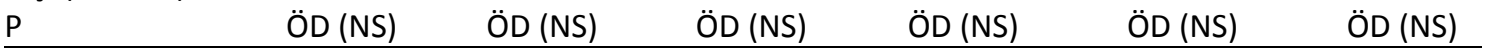

Sırt yüksekliği, $\mathrm{cm}$ (ridge height, $\mathrm{cm}$ )

Erkek (Male) $962.11 \pm 1.50774 .43 \pm 1.341076 .80 \pm 1.54 \quad 476.50 \pm 2.78 \quad 4 \quad 76.00 \pm 1.29 \quad 3472.29 \pm 1.29$ Dişi (Female) $\quad 2559.08 \pm 1.583566 .80 \pm 0.635969 .55 \pm 0.40 \quad 3569.49 \pm 0.58 \quad 1370.23 \pm 0.80 \quad 16767.45 \pm 0.44$ \begin{tabular}{lllllll}
$\mathrm{P}$ & ÖD (NS) & $* *$ & $* *$ & $* *$ & $* *$ & $* *$ \\
\hline
\end{tabular} Sağrı yüksekliği, $\mathrm{cm}$ (rump height, $\mathrm{cm}$ )

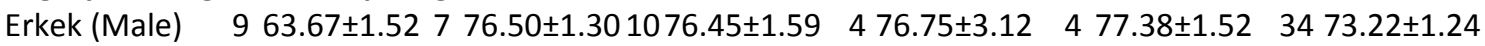
Dişi (Female) $\quad 2562.00 \pm 0.923568 .27 \pm 0.635969 .04 \pm 0.41 \quad 3569.14 \pm 0.57 \quad 1369.69 \pm 0.83 \quad 16768.80 \pm 0.37$

\begin{tabular}{lllllll}
$\mathrm{P}$ & ÖD (NS) & $* *$ & $* *$ & $* *$ & $* *$ & $* *$ \\
\hline
\end{tabular}

Göğüs çevresi, cm (chest girth, $\mathrm{cm}$ )

Erkek (Male) $978.22 \pm 2.44798 .86 \pm 1.7910100 .80 \pm 1.554102 .25 \pm 1.934108 .50 \pm 1.943495 .50 \pm 2.06$ Dişi (Female) $\quad 2575.22 \pm 1.423586 .80 \pm 0.755988 .56 \pm 0.65 \quad 3590.23 \pm 0.89 \quad 1391.39 \pm 1.37 \quad 16786.85 \pm 0.55$ $\begin{array}{lllllll}\mathrm{P} & \text { ÖD (NS) } & * * & * * & * * & * * & * *\end{array}$

Göğüs derinliği, $\mathrm{cm}$ (chest depth, $\mathrm{cm}$ )

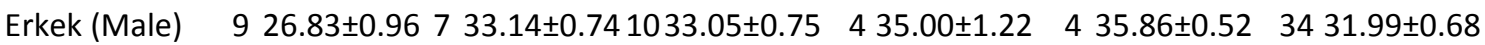
$\begin{array}{llllll}\text { Dişi (Female) } \quad 2525.32 \pm 0.433529 .79 \pm 0.335931 .93 \pm 0.21 & 3530.93 \pm 0.39 & 1331.00 \pm 0.41 & 16730.21 \pm 0.23\end{array}$

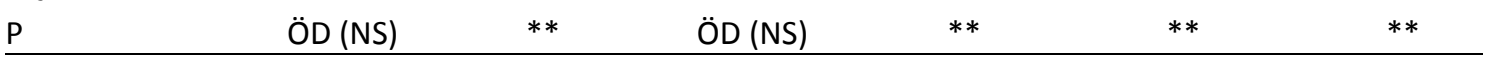

Kulak uzunluğu, $\mathrm{cm}$ (ear length, $\mathrm{cm}$ )

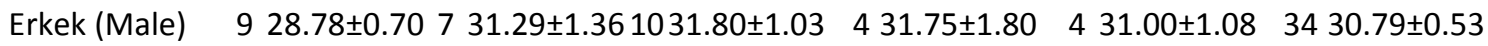
Dişi (Female) $\quad 2527.72 \pm 0.353529 .67 \pm 0.425930 .46 \pm 0.38 \quad 3530.83 \pm 0.50 \quad 1330.15 \pm 0.60 \quad 16729.92 \pm 0.22$ PÖD (NS) ÖD (NS) ÖD (NS) $\quad$ ÖD (NS) $\quad$ ÖD (NS) $\quad$ ÖD (NS) Ön İncik Çevresi,cm (fore cannon girth, cm)

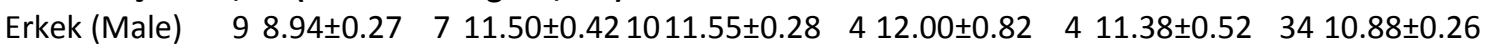

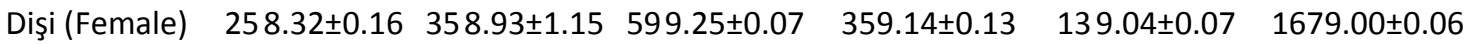

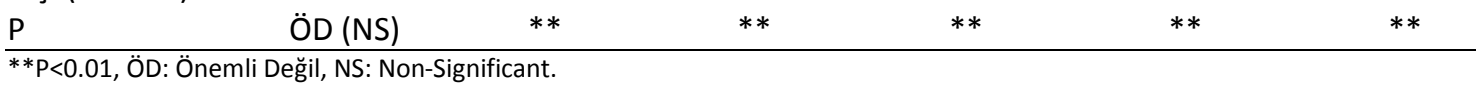

Çizelge 1'den, Kilis keçilerinde canlı ağırlık, vücut uzunluğu, cidago yüksekliği, göğüs genişliği, sırt yüksekliği, sağrı yüksekliği, göğüs çevresi, göğüs derinliği, kulak uzunluğu ve ön incik çevresi genel ortalamalarının erkekler için sırasıyla $59.68 \pm 3.64 \mathrm{~kg}, 74.07 \pm 1.55 \mathrm{~cm}, 76.24 \pm 1.49$ $\mathrm{cm}, \quad 21.57 \pm 0.55 \mathrm{~cm}, \quad 72.29 \pm 1.29 \mathrm{~cm}$, 
$73.22 \pm 1.24 \mathrm{~cm}, 95.50 \pm 2.06 \mathrm{~cm}, 31.99 \pm 0.68$ $\mathrm{cm}, 30.79 \pm 0.53$ ve $10.88 \pm 0.26 \mathrm{~cm}$ olarak; dişiler için ise sırasıyla $41.43 \pm 0.70 \mathrm{~kg}$, $69.75 \pm 0.48 \mathrm{~cm}, 69.06 \pm 0.38 \mathrm{~cm}, 20.81 \pm 0.20$ $\mathrm{cm}, \quad 67.45 \pm 0.44 \mathrm{~cm}, \quad 68.80 \pm 0.37 \mathrm{~cm}$, $86.85 \pm 0.55 \mathrm{~cm}, 30.21 \pm 0.23 \mathrm{~cm}, 29.92 \pm 0.22$ $\mathrm{cm}$ ve $9.00 \pm 0.06 \mathrm{~cm}$ olduğu görülmektedir. Incelenen tüm bu özelliklerin cinsiyetlere göre genel ortalamaları karşılaştırıldığında, göğüs genişliği ve kulak uzunluğu dışındaki özelliklerin genel ortalamaları arasındaki farkın önemli $\quad(P<0.01)$ olduğu da görülmektedir. Bu özellikler bakımından erkeklerin dişilerden yaklaşık \%44 daha fazla canlı ağırlığa, \%6 daha fazla vücut uzunluğuna, \%10 daha fazla cidago yüksekliğine, \%4 daha fazla göğüs genişliğine, $\% 7$ daha fazla sırt yüksekliğine, \%6 daha fazla sağrı yüksekliğine, \%10 daha fazla göğüs çevresine, \%6 daha fazla göğüs derinliğine, \%3 daha fazla kulak uzunluğuna ve \%21 daha fazla ön incik çevresine sahip olduğu görülmüştür.
Ayrıca, tüm bu özellikler yaş grupları içinde cinsiyetlere göre karşılaştırıldığında, bir yaşındaki keçilerde tüm bu özellikler arasındaki farkın önemli olmadığı ( $P>0.05)$, daha sonraki yaşlardaki keçilerde ise kulak uzunluğu ve göğüs genişliği dışındaki diğer özelliklerin ortalamaları arasındaki farkın önemli olduğu $(P<0.01)$ saptanmıştır. Tüm bu sonuçlardan, cinsiyet etkisinin Kilis keçilerinin göğüs genişliği ve kulak uzunluğu dışındaki diğer vücut özellikleri ile canlı ağırlık genel ortalamaları üzerinde istatistik olarak önemli olduğu; ancak, cinsiyet etkisinin bir yaşlı keçilerde tüm bu özellikler üzerinde önemsiz $(P>0.05)$, sonraki yaşlarda ise 3 yaşlı keçilerde göğüs derinliği dışında, cinsiyetin önemli olduğu sonucuna varılmıştır.

Kilis keçilerde incelenen tüm bu özellikler arasındaki korelasyonlar Çizelge 2'de verilmiştir.

Çizelge 2. Incelenen özellikler arasındaki fenotipik korelasyonlar

Table 2. Phenotypic correlations between the studied characteristics

\begin{tabular}{|c|c|c|c|c|c|c|c|c|c|}
\hline $\begin{array}{l}\text { Özellikler } \\
\text { (Charecteristic) }\end{array}$ & VUCUZN & CIDYUK & GOGGEN & SRTYUK & SAGYUK & GOGCEV & GOGDER & KULUZN & OIC \\
\hline CANAGR & $0.86^{* *}$ & $0.89 * *$ & $0.65^{* *}$ & 0.10 & $0.87 * *$ & $0.88^{* *}$ & $0.83^{* *}$ & $0.44 * *$ & $0.81 * *$ \\
\hline VUCUZN & & $0.89 *$ & $0.76^{* *}$ & 0.01 & $0.86 * *$ & $0.82 * *$ & $0.85^{* *}$ & $0.44 * *$ & $0.65^{* *}$ \\
\hline CIDYUK & & & $0.65^{* *}$ & $0.15^{*}$ & $0.93 * *$ & $0.79 * *$ & $0.77^{* *}$ & $0.41 * *$ & $0.73^{* *}$ \\
\hline GOGGEN & & & & -0.05 & $0.66 * *$ & $0.75^{* *}$ & $0.75^{* *}$ & $0.30 * *$ & $0.45^{* *}$ \\
\hline SRTYUK & & & & & 0.11 & -0.01 & 0.03 & -0.03 & $0.21^{* *}$ \\
\hline SAGYUK & & & & & & $0.81 * *$ & $0.80 * *$ & $0.44 * *$ & $0.69 * *$ \\
\hline GOGCEV & & & & & & & $0.86^{* *}$ & $0.41 * *$ & $0.71^{* *}$ \\
\hline GOGDER & & & & & & & & $0.41^{* *}$ & $0.61^{* *}$ \\
\hline KULUZN & & & & & & & & & $0.42 * *$ \\
\hline
\end{tabular}

CANAGR: Canlı Ağırlık (Body Wight), VUCUZN : Vücut Uzunluğu (Body Length), CIDYUK: Cidago Yüksekliği (Withers Height), GOGGEN: Göğüs Genişliği (Chest Width), SRTYUK: Sırt Yüksekliği (Ridge Height), SAGYUK: Sağrı Yüksekliği (Rump Height), GOGCEV: Göğüs Çevresi, (Chest Girth), GOGDER: Göğüs Derinliği (Chest Depth), KULUZN: Kulak Uzunluğu (Ear Length), OIC: Ön İncik Çevresi (Fore Cannon Girth), **: $\mathrm{P}<0.01 *: \mathrm{P}<0.05$ 
Çizelge 2'den de görüldüğü üzere, Kilis keçilerinde canlı ağırlık ile diğer vücut özellikleri arasındaki korelasyonların (sırt yüksekliği hariç $r=0.10, P>0.05$ ) pozitif yönde oldukça yüksek (0.44 ile 0.89 arasında) ve önemli $(P<0.01)$ olduğu görülmektedir. En yüksek korelasyonların, canlı ağırlık ile cidago yüksekliği ve göğüs çevresi arasında (sırasıyla 0.89 ve 0.88 ) olduğu tespit edilmiştir.

Bu çalışmada, farklı yaşlardaki (1, 2, 3, 4 ve $5+)$ Kilis keçilerinde genel ortalama canlı ağırlık erkeklerde $59.68 \pm 3.64 \mathrm{~kg}$ olarak, dişilerde ise $41.43 \pm 0.70 \mathrm{~kg}$ olarak belirlenmiştir. Bu sonuç Keskin ve Tüney (2015), teke katımı öncesi Kilis keçilerinde bildirdiği canlı ağırlıklar $(45.3 \mathrm{~kg})$ ile AlızadehasI ve Ünal (2011), Kilis keçileri için saptadıkları (47.1 kg) canlı ağılık değerlerinden daha düşük bulunmuştur. Bu farklııklar işletme, yıl, bakım, besleme vb. gibi çevresel faktörlerinden kaynaklanmış olabilir.

Elmaz ve ark., (2012)'nin Honamlı keçileri ve tekeleri için bildiridikleri ergin canlı ağırlık (63.5 kg ve $77.3 \mathrm{~kg}$ ), Gök ve ark., (2015)'in Honamlı keçi ve tekeleri için bildirdikleri canlı ağırlık değerleri (66.6 kg ve $98.3 \mathrm{~kg}$ ) bu çalışma sonuçlarından daha yüksektir. Ancak, Rahman ve ark., (2008), 12 ve 15 aylık yaştaki Black Bengal tekelerde bildirdikleri canlı ağrılık (16.56 \pm 0.57 ve $21.82 \pm 0.70 \mathrm{~kg}$ ) Kilis keçilerinde belirlenen bir yaş canlı ağırlık bulgularından $\quad(29.20 \pm 2.22 \mathrm{~kg})$ daha düşüktür.

Bu çalışmada Kilis ırkı dişi keçiler için elde edilen vücut uzunluğu $69.75 \pm 0.48 \mathrm{~cm}$ 'dir. AlızadehasI ve Ünal (2011), Kilis keçilerinde (71.9 cm), Gök ve ark., (2015) Honamlı keçilerde $(84,1 \mathrm{~cm})$ ve Elmaz ve ark., (2012), Honamlı keçileri için bildirdiği vücut uzunluğu $(88.3 \mathrm{~cm})$ sonuçları, bu çalışmadan elde edilen değerden daha yüksektir. Ancak, Bingöl ve ark., (2011)'in Norduz keçilerinde saptadığı vücut uzunluğu $(67.15 \pm 1.08)$ bu çalışmadan elde edilen değerden daha düşüktür.

Kilis keçilerde Barıtcı ve Eliçin (2002)'in bildirdiği sırt yüksekliği $(52.80 \mathrm{~cm})$ bu çalışma bulgusundan $(67.45 \pm 0.44 \mathrm{~cm})$ daha düşük, ancak Gök ve ark., (2015), Honamlı ırkı dişiler için bildirdiği sağrı yüksekliği $(82.2 \mathrm{~cm})$ bu çalışma sonucundan daha yüksek bulunulmuştur.

Çalışmada, Kilis keçilerin sağrı yüksekliği $68.80 \pm 0.37 \mathrm{~cm}$ olarak belirlenmiştir. Bu sonuç Barıtcı ve Eliçin (2002), Kilis keçileri $(54.32 \mathrm{~cm})$ için bildirdiği değerden yüksek ancak Alızadehasl ve Ünal (2011), Kilis keçilerinde $(70.3 \mathrm{~cm})$ ve Elmaz ve ark., (2012), Honamlı keçilerinde $(83.3 \mathrm{~cm})$ bildirdiği değerlerden daha düşüktür.

Barıtcı ve Eliçin (2002), Kilis keçilerde bildirdikleri göğüs çevresi $(56.82 \mathrm{~cm})$ değeri bu çalışmada bulunan göğüs çevresi $(86.85 \pm 0.55 \mathrm{~cm})$ sonuçlarından düşük, ancak Alızadehasl ve Ünal (2011), Kilis keçilerinde $(85.2 \mathrm{~cm})$ ve Gök ve ark., (2015), Honamlı keçilerinde (100.2 cm), Elmaz ve ark., (2012), Honamlı keçilerde $(91.0 \mathrm{~cm})$, Bingöl ve ark., (2011), Norduz keçilerinde $(88.87 \mathrm{~cm})$ saptanan göğüs çevresi ise bu çalışma sonuçlarından daha yüksektir.

Gök ve ark., (2015), Honamlı keçilerde bildirdiği göğüs derinliği $(35.4 \mathrm{~cm})$ ve Alızadehasl ve Ünal (2011), Kilis keçilerinde bildirdiği göğüs derinliği $(31.9 \mathrm{~cm})$ bu çalışma bulgularından $(30.21 \pm 0.23 \mathrm{~cm})$ daha yüksek, ancak Bingöl ve ark., (2011), Norduz keçileri için bildirdiği değerler ile benzerlik gösterdiği (30.78 \pm 0.62$)$ görülmüştür.

Barıtcı ve Eliçin (2002), Kilis keçilerde bildirdiği ön incik çevresi $(7.18 \mathrm{~cm})$ bu çalışma sonucundan daha düşük, ancak AlızadehasI ve Ünal (2011), Kilis keçilerinde $(10.1 \mathrm{~cm})$ ve Elmaz ve ark., (2012), Honamlı keçilerinde $(10.2 \mathrm{~cm})$ bildirdiği sonuçlar bu 
çalışmadan elde edilen ön incik çevresi $(9.00 \pm 0.06 \mathrm{~cm})$ değerinden daha yüksektir.

Bu çalışmada, canlı ağırlık ile vücut uzunluğu (0.86), cidago yüksekliği (0.89), göğüs genişliği (0.65), sağrı yüksekliği (0.87), göğüs çevresi (0.88), göğüs derinliği (0.83), kulak uzunluğu (0.44) ve ön incik çevresi (0.81) arasındaki korelasyon pozitif yönde ve önemli $\quad(\mathrm{P}<0.01)$ bulunmuştur. Vücut uzunluğu ile cidago yüksekliği, göğüs genişliği, sağrı yüksekliği, göğüs derinliği, kulak uzunluğu ve ön incik çevresi uzunluğu arasında pozitif ve önemli $(P<0.01)$ korelasyon belirlenmiştir. Rahman ve ark., (2008), Black Bengal tekelerde canlı ağırlık ile göğüs çevresi (0.94), vücut uzunluğu (0.95), cidago yüksekliği (0.96) arasında pozitif önemli ve yüksek korelasyon olduğunu bildirmiştir. Çam ve ark., (2010), Kıl keçilerde canlı ağırlık ile sağrı yüksekliği, cidago yüksekliği, vücut uzunluğu, göğüs genişliği, göğüs çevresi, göğüs derinliği gibi ölçüler arasındaki korelasyonları inceldikleri çalışmada canlı ağırlık ile göğüs çevresi arasında (0.847), canlı ağırlık ile göğüs derinliği arasında (0.775), göğüs çevresi ve göğüs derinliği arasında (0.973), göğüs çevresi ile göğüs genişliği arasında (0.667), cidago yüksekliği ile sağrı yüksekliği arasında (0.823) önemli düzeyde pozitif ve yüksek korelasyon olduğunu saptamışlardır.

\section{Sonuçlar}

Kilis keçilerinde cinsiyetin, beklenildiği şeklide; canlı ağırlık, vücut uzunluğu, cidago yüksekliği, göğüs çevresi, sırt yüksekliği, sağrı yüksekliği, göğüs çevresi ve incik çevresi ölçüleri gibi bir çok vücut özelliği üzerinde önemli etkisinin olduğu; ancak göğüs genişliği ve kulak uzunluğu üzerindeki etkisinin önemli olmadığı görülmüştür. Cinsiyetin bu etkisinin özellikle bir yaşlı keçilerde incelenen tüm bu özellikler üzerinde önemli bir etkiye sahip olmaması ve sonraki yaşlarda önemli hale (3 yaş göğüs derinliği dışında) gelmesi de saptanan bir diğer önemli bulgu olarak görülebilir. Ayrıca, Kilis keçilerinde canlı ağırlık ile diğer bazı vücut ölçüleri arasında pozitif ve önemli ilişkinin olduğu da bu çalışmayla tespit edilmiştir. Bu tespit, özellikle canlı ağırlık tartımlarının yapılamadığı yetiştirici şartlarında, daha kolay alınabilecek diğer vücut ölçümlerinin kullanılarak keçi yetiştiricilerinin bu yönde alacakları kararlarda, özellikle de ıslah çalışmalarında isabeti artıracak önemli bilgiler olarak değerlendirilebilir.

\section{Kaynaklar}

Alızadehasl, M., Ünal, N., 2011. Kilis, Norduz ve Honamlı keçilerinde bazı morfolojik özellikler. Lalahan Hayvancilık Araştırma Enstitüsü Dergisi, 51 (2): 81-92.

Anonim, 2004. Yerli Hayvan Irk ve Hatlarının Tescili Hakkında Tebliğ Tebliğ No: 2004/39. Ek-28: Kilis Keçisi (Ek:RG-22/04/200626147). Resmi Gazete Tarihi: 12.12.2004 Resmi Gazete Sayısı: 25668 (Erişim Tarihi: 04.11.2016).

Barıtcı, İ., Elçin, A., 2002. Kilis keçisi oğlaklarında doğumda, 3 ve 6 aylık yaşta vücut ölçüleri arasındaki ilişkilerin kanonik korelasyon metodu ile araştırılması. GOÜ Ziraat Fakültesi Dergisi, 19(1): 137-144.

Bingöl, M., Gökdal, Ö., Aygün, T., Yılmaz, A., Daşkıran, i., 2011. Norduz keçilerinde bazı tanımlayıcı verim özellikleri ve vücut ölçüleri. 7. Ulusal Zootekni Bilim Kongresi, 14-16 Eylül 2011.

Ceyhan, A., 2016. Türkiye'de neden keçi yetiştirmeliyiz? AGROMEDYA Dergisi, 25: 100-104.

Çam, M.A., Olfaz, M., Soydan, E., 2010. Possibilities of using morphometric characteristics as a tool for body weight prediction in Turkish Hair Goats (Kilkeci). Asian Journal of Animal and Veterinary Advances, 5(1): 52-59.

Elmaz, Ö., Saatcı, M., Mamak, N., Dağ, B., Aktaş, A.H., Gök, B., 2012. Türkiye'de yeni bir yerli ırk olarak tanımlanan Honamlı keçi ve 
oğlaklarının bazı morfolojik özelliklerinin belirlenmesi. Kafkas Üniversitesi Veteriner Fakültesi Dergisi, 18 (3): 481-485.

Gök, B., Aktaş, A.H,. Halıcı, I, Baş, H., 2015. Halk elinde koruma altına alınan Honamlı keçisi ve oğlaklarının canlı ağırlıkları ve bazı vücut ölçüleri. Eurasian Journal of Veterinary Sciences, 31(4): 227-234.

Keskin, M., Tüney, D., 2015. Kilis keçilerinde vücut kondisyon puanı ve döl verimi arasındaki ilişki. Mustafa Kemal Üniversitesi Ziraat Fakültesi Dergisi, 20(2): 60-65.

Özcan, L., 1989. Küçükbaş Hayvan Yetiştirme-1 (Keçi üretimi). Birinci Baskı, Ç.Ü. Ziraat Fakültesi Ders Kitabı No: 111, Ziraat Fakültesi Ofset ve Teksir Atölyesi, Adana, Türkiye, 228-231s.

Rahman, A. H. M. S., Khandoker, M. A. M. Y., Husain, S. S., Apu, A. S., Mondal, A., Notter, D. R., 2008. Morphometric characterization and relationship of body weight with linear body measurements in Black Bengal buck. Bangladesh Journal of Animal Science, 37(2): 8-16.

SPSS, 2004. SPSS for Windows Ver. 17.0, SPSS Inc., Chicago, Illinois, USA.

TÜiK, 2016. Hayvansal Üretim. http://www.tuik.gov.tr/UstMenu.do?me tod=temelist (Erişim Tarihi: 01.11.2016).

Ünalan, A., 2007. Gen kaynaklarının halk elinde korunması (Kilis sığırı, Yerli Güney Sarısı ve Kilis keçisi). https://www.researchgate. net/publication/292078457_Gen_Kaynak larinin_Halk_Elinde_Korunmasi_Kilis_Sigiri _Yerli_Guney_Sarisi_Kilis_Kecisi (Erişim Tarihi: 02.11.2016). 